\title{
PAISAGENS RESIDUAIS E MUSEU DO VINHO: PATRIMÔNIO VITIVINÍCOLA NO SUL DE MINAS GERAIS
}

\author{
Residual landscapes and wine museum: \\ wine heritage in south Minas Gerais \\ Paisajes residuales y museo del vino: \\ patrimonio del vino en el sur de Minas Gerais \\ Marcelo Cervo Chelotti * \\ Rosa Maria Viera Medeios** \\ * Doutor em geografia pela UFU e Pós-doutorado pela UFRGS \\ - chelotti@ufu.br \\ ** Doutora em geofrafia pela Université de Poitiers e Pós-doutorado no GREGUM \\ - rmvmedeiros@ufrgs.com
}

\section{Resumo:}

O presente artigo teve como objetivo discutir as expressões do patrimônio associado ao cultivo da uva e do fabrico do vinho no sul de Minas Gerais, em especial nos municípios de Caldas e Andradas. Em relação aos procedimentos metodológicos, esses foram divididos em duas etapas, a pesquisa bibliográfica, e pesquisa de campo com objetivo de coletar os primários nos municípios, realizada em e julho de 2018. Os resultados demonstraram que a centenária tradição em cultivar a uva e fabricar o vinho produziram inegavelmente fortes traços identitários no sul mineiro, constituindo um significativo patrimônio associado as expressões materiais e imateriais da vitivinicultura. As marcas da tradicional vitivinicultura na paisagem estão cada vez mais residuais, mas por outro lado a salvaguarda desse patrimônio pode ser garantida a partir da criação do Museu do Vinho.

Palavras-chave: Patrimônio Vitivinícola. Paisagens Residuais. Museu do Vinho. Sul de Minas Gerais.

\begin{abstract}
:
This paper aims to discuss the expressions of heritage associated with grape cultivation and wine making in southern Minas Gerais, especially in the municipalities of Caldas and Andradas. Regarding the methodological procedures, these were divided into two stages, the bibliographic research, and field research aiming to collect the primaries in the municipalities, carried out in and July 2018. The results showed that the centuries-old tradition of cultivating grapes and manufacturing The wine undeniably produced strong identity traits in the south of Minas Gerais, constituting a significant heritage associated with the material and immaterial expressions of winemaking. The marks of traditional viticulture in the landscape are increasingly residual, but on the other hand the safeguarding of this heritage can be guaranteed from the creation of the Wine Museum.
\end{abstract}

Keywords: Wine Heritage. Residual landscapes. Wine Museum. South of Minas Gerais. 


\begin{abstract}
Resumen:
Este articulo tiene como objetivo discutir las expresiones del patrimonio asociadas con el cultivo de la uva y la vinificación en el sur de Minas Gerais, especialmente en los municipios de Caldas y Andradas. En cuanto a los procedimientos metodológicos, estos se dividieron en dos etapas, la investigación bibliográfica y la investigación de campo con el objetivo de recolectar las primarias en los municipios, realizadas en julio de 2018. Los resultados mostraron que la tradición centenaria de cultivar uvas y fabricación El vino indudablemente produjo fuertes rasgos de identidad en el sur de Minas Gerais, lo que constituye un importante patrimonio asociado con las expresiones materiales e inmateriales de la vinificación. Las marcas de la viticultura tradicional en el paisaje son cada vez más residuales, pero, por otro lado, la salvaguardia de este patrimonio se puede garantizar desde la creación del Museo del Vino.
\end{abstract}

Palabras clave: Patrimonio del vino. Paisajes residuales. Museo del vino Al sur de Minas Gerais.

\title{
1. Introdução
}

Embora não tenha uma larga tradição na produção de vinhos, como ocorre em muitos países europeus, no Brasil existe um considerável patrimônio vitivinícola que merece ser preservado. Há que se destacar também que esse patrimônio não se encontra localizado somente em territórios tradicionais do vinho como o Rio Grande do Sul, mas também em Santa Catarina, Paraná, São Paulo e Minas Gerais.

As recentes discussões sobre as expressões territoriais da vitivinicultura, sejam elas associadas às práticas tradicionais do saber fazer o vinho (colonial/artesanal), ou as novas práticas associadas a saber fazer associado aos processos modernos (finos/castas), produzindo novas ruralidades associadas a uva e ao vinho. Portanto, faz-se necessário compreender as expressões contemporâneas da vitivinicultura, ou melhor, dos novos e velhos territórios da uva do vinho.

\begin{abstract}
Esse prisma patrimonial e cultural do vinho suscita numerosas pesquisas, como por exemplo, sobre os processos de constituição histórica das regiões vinícolas, sua preparação e organização para fins turísticos, econômicos ou ambientais. Urge, pois, no Brasil, a necessidade de pesquisas sobre a preservação da memória, da cultura e do patrimônio do vinho brasileiro, sob pena de se perder esses elementos no tempo e no espaço impossibilitando as futuras gerações de conhecerem sua história, sua memória (MEDEIROS, 2017, p. 13)
\end{abstract}

Para Cavicchioli (2013) o vinho passou a ocupar um espaço bastante especial no rol do patrimônio cultural, sendo que uma das preocupações atuais reside na preservação deste patrimônio cultural do vinho. Acreditamos, que a divulgação e o acesso das pesquisas a um público leigo ou não acadêmico é um elemento essencial na preservação e valorização do patrimônio cultural do vinho, pois, na medida em que as pessoas o conhecem podem identificar-se com ele, compreendendo ser de interesse público a sua preservação.

Para0nde!?, Porto Alegre, v.13, n.1, p.01-20, 2020. http://seer.ufrgs.br/paraonde 
O patrimônio e a cultura do vinho no Brasil de maneira ampliada requerem investimentos em pesquisa e ensino de qualidade, a exemplo de outros países, como França, Portugal, Espanha, entre outros. Há carência de informações, dados e conhecimentos nesse campo, e o patrimônio do vinho no Brasil, com poucas exceções, vai se perdendo a cada ano (VALDUGA, 2015).

O estudo da Geografia das regiões, na ótica dos territórios, da cultura e do patrimônio da uva e do vinho, evidenciou que há no Brasil, estados e regiões com identidade vitivinícola, cuja relevância enseja pesquisas específicas (FALCADE, 2017).

Assim, motivados pela provocação de Medeiros (2017), Valduga (2015), e Falcade (2017), a presente pesquisa teve como discutir as expressões do patrimônio associado ao cultivo da uva e do fabrico do vinho no sul de Minas Gerais, em especial nos municípios de Caldas e Andradas (Mapa 1), bem como caracterizar esses municípios enquanto territórios do vinho e da cultura vitivinícola.

Mapa 1 - Minas Gerais: localização dos municípios pesquisados

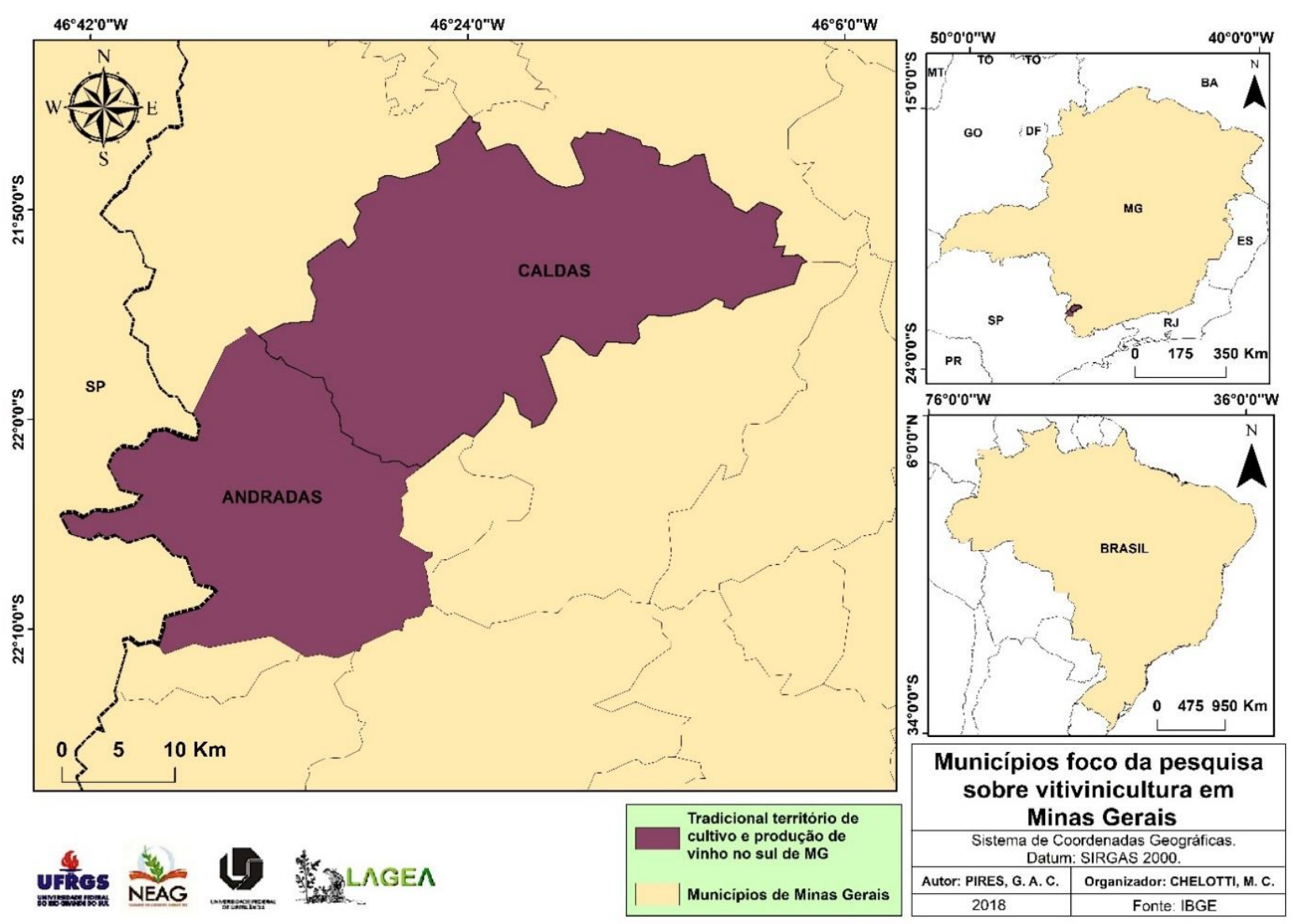

Os municípios sul mineiros de Andradas e Caldas se apresentam enquanto excelente laboratório para discutirmos as expressões contemporâneas da vitivinicultura. Ao mesmo tempo que possuem uma secular tradição no cultivo da uva e do fabrico do vinho, também são palco de novas experiências na modernização da vitivinicultura no Brasil tropical. Assim, tradição e 
modernidade comparecem lado a lado na vitivinicultura do sul de Minas Gerais. Por um lado, é crescente as paisagens

Os municípios sul mineiros de Andradas e Caldas se apresentam enquanto excelente laboratório para discutirmos as expressões contemporâneas da vitivinicultura. Ao mesmo tempo que possuem uma secular tradição no cultivo da uva e do fabrico do vinho, também são palco de novas experiências na modernização da vitivinicultura no Brasil tropical. Assim, tradição e modernidade comparecem lado a lado na vitivinicultura do sul de Minas Gerais. Por um lado, é crescente as paisagens residuais de uma vitivinicultura tradicional, e por outro, é evidente uma nova vitivinicultura alicerçada em novos paradigmas técnico-científicos.

O espaço se organiza de forma distinta em razão da expansão da viticultura. O vinho, pouco a pouco, ocupa espaços com a instalação de novas vinícolas ou com a expansão das antigas nos novos territórios. São esses territórios que atraem turistas ávidos em explorar e consumir de forma lenta e suave os produtos locais plenos de sabores e saberes (MEDEIROS, 2017, p. 9).

Em relação aos procedimentos metodológicos, esses foram divididos em etapas, sendo elas: A primeira etapa correspondeu a pesquisa bibliográfica, distribuída nos meses de fevereiro, março e abril de 2018 primeiros meses das atividades. Destaca-se que em relação ao levantamento bibliográfico, buscamos nas principais obras teóricas discussões que contribuíssem como a pesquisa em curso enriquecendo e alicerçando a elaboração dos resultados e consequentemente a interface entre a teoria e a práxis.

Nessa trajetória de compreendermos as expressões contemporâneas do patrimônio vitivinicultura no sul de Minas Gerais, a categoria paisagem foi central na questão metodológica. Pois para Cosgrove (2012, p. 229) os múltiplos significados das paisagens simbólicas aguardam decodificação geográfica. Os dois principais caminhos para isso são o trabalho de campo e a elaboração e a interpretação de mapas. O tipo de incidência que os geógrafos usam agora para interpretar o simbolismo das paisagens culturais é muito mais amplo do que no passado. Evidência material no campo e outras fontes documentais e cartográficas, orais, de arquivo e outras continuam valiosas.

A pesquisa de campo então, foi realizada em julho de 2018. Para tal definimos duas frentes de trabalho: (a) nos primeiros dias nos dedicamos a visitar as instituições, tais como EMATER, EPAMIG e Prefeitura Municipal. No município de Andradas visitamos a Casa da Cultura, que possui rico acervo sobre a história da vitivinicultura local. Também visitamos a secretaria municipal de Agricultura, Turismo e Lazer, onde tivemos acesso as discussões sobre o Plano Museológico do Museu do Vinho de Andradas. No município de Caldas visitamos a EPAMIG, onde podemos conhecer de perto os projetos de melhoramento vitícola em curso, bem como suas instalações industriais e parreirais com diversas cepas plantadas. Outra visita importante foi realizada na EMATER, no qual foi possível ter contato com os nomes dos vitivinicultores, bem como seus endereços. Também visitamos a Casa de Cultura de Caldas que contém rico acervo sobre a tradição da vitivinicultura no município.

Outra estratégia metodológica utilizada no decorrer da pesquisa de campo

Para0nde!?, Porto Alegre, v.13, n.1, p.01-20, 2020. http://seer.ufrgs.br/paraonde 
foi a prática do Diário de Campo. Depois de um dia inteiro de atividades de campo, tomamos como prática a sistematização das informações obtidas em forma de diário.

Saindo de Pocinhos em direção a Pedra Branca, foram identificados apenas 4 parreirais no caminho. Sendo que um em completo abandono (vestígios de mourões e arames no meio de um capinzal seco típico do inverno), dois parreirais em sistema de espaldeira, e um em sistema de latada. Possivelmente todos com a uva Folha de Figo. Muito presente na paisagem as taperas. Algumas roças servindo de segunda residência. Assim, evidencia-se a viticultura como Paisagem Residual. A pecuária leiteira extensiva é predominante na paisagem. (Diário de Campo, Domingo dia 22 de julho de 2018)

Outra atividade de campo que realizamos, foi a participação no dia 20 de julho na 53 ${ }^{\text {a }}$ Festa do Vinho de Andradas. Durante a festividade pudemos fazer uma observação participante, e perceber como a Festa do Vinho tem repercussão regional. Durante o dia fomos na praça central da cidade observar o memorial da Festa do Vinho.

Diante do exposto, organizamos o presente texto em x partes. Na primeira, apresentamos a vitivinicultura na perspectiva do patrimônio. Na segunda, nos dedicamos as paisagens residuais e as taperas do vinho. Já na terceira parte, trazemos uma sistematização dos museus do vinho. A quarta parte, é dedica ao processo de construção do museu do vinho de Andradas. E, por fim, tecemos nossas considerações finais.

\section{A vitivinicultura enquanto patrimônio}

A existência de um considerável patrimônio cultural associado a tradição do cultivo da uva e do fabrico do vinho, possibilitou em 2006 a formação da Chaire UNESCO " Culture et Traditions du Vin ${ }^{1}$ pela Universidade da Borgonha/França. A cátedra está ancorada numa rede internacional de parceiros do mundo acadêmico, do mundo profissional vitivinícola e de empresas, do mundo cultural, do mundo institucional. Ainda envolve dezenas de países de "antigos" e de "novos vinhedos" de todos continentes.

Dentre os seus objetivos da Cátedra, podemos destacar: (a) Pesquisar a parte da herança cultural na geografia, nas práticas culturais ou enológicas, na organização, na valorização e a produção de "antigos vinhedos"; (b) Analisar os motivos do desenvolvimento de "novos vinhedos" ou ainda a emergência de "vinhedos externos" em regiões onde, a priori o ambiente não permitiria a videira.

\footnotetext{
${ }^{1}$ Uma cátedra da UNESCO é constituída de uma rede internacional de parceiros que propõem um projeto em comum em torno de uma problemática podendo sustentar programas prioritários, tais como

a difusão da educação e da pesquisa, a cultura, a igualdade de oportunidades, o ambiente e o desenvolvimento durável ou ainda a paz e a governabilidade e também a salvaguarda do patrimônio (CÁTEDRA UNESCO, 2018).
} 
Os aspectos patrimoniais e culturais da vinha e do vinho estão, de agora em diante, integrados à valorização das regiões vinícolas, em todo o mundo. A classificação de 09 vinhedos, todos europeus, como patrimônio mundial da UNESCO no curso dos últimos 15 anos tem mostrado como o patrimônio do vinho, material e imaterial, constitui um vetor significativo de desenvolvimento econômico e turístico e, atualmente, muitas regiões preparam ou submetem suas candidaturas à UNESCO (LUCCA FILHO et al, 2013).

Nesse contexto, em países do novo mundo (Argentina, África do Sul, Brasil e Chile) podemos observar a formação de uma identidade territorial associada ao cultivo da uva e do fabrico do vinho. No Brasil, em especial na Serra Gaúcha, o desenvolvimento da vitivinicultura se deu associada a migração italiana no século XIX. O cultivo da uva em pequenas propriedades familiares imprimiu na paisagem e fortes marcas identitárias, em que parreirais de uvas, cantinas e 0 vinho são marcas que estão impressas no território e que culturalmente transformaram-se em uma identidade territorial (DUARTE; FERNANDES, 2014).

Nesse desafio de pesquisar novas e velhas regiões vitivinícolas, não podemos negligenciar as experiências existentes em outras partes do território brasileiro. E é, nesse cenário, que se insere o estado de Minas Gerais, localizado na região sudeste, reconhecido pelos excelentes cafés e cachaças. No entanto, no sul mineiro a produção de vinho tem uma tradição que remonta ao final do século XIX e início do XX.

De antemão, destacamos alguns elementos que corroboram com a formação da identidade territorial vitivinícola no sul mineiro em especial em Andradas e Caldas: (a) A existência da Festa da Uva e Festa do Vinho que vem sendo realizadas desde a década 1950; (b) O papel histórico desempenhado pela EPAMIG/Caldas desde os anos 1930 na difusão de tecnologia vitivinícola; (c) $O$ patrimônio material das antigas adegas; (d) $\mathrm{O}$ patrimônio imaterial contido nos modos de cultivar a uva e fabrico do vinho; (e) A paisagem vinícola; e (f) as novas experiências no cultivo e na fabricação do vinho que indicam uma atividade viva, e não em extinção.

Sendo assim, durante o processo de formação dessa identidade territorial também se formou um patrimônio cultural vitivinícola, pois na medida em que o tempo passa são materializados no território distintas marcas do cultivar a uva e de fabricar o vinho. No caso do município de Andradas (MG) existe a tradição da vitivinicultura, como um traço da predominância da colonização italiana, que por meio das famílias que se instalaram, passaram a reproduzir seus costumes e a técnica de cultivo da uva e produção de vinhos.

\footnotetext{
É notável a tradição vitivinícola no município de Andradas, resguardada pelos produtores, que, em sua inscrição terrestre, têm a uva, o vinho e o modo de vida relativo a eles como valores geográficos (KALIL, 2016, p.62)

Assim, o passado foi reconstituído neste estudo tendo como principal fonte as histórias orais das famílias produtoras de vinho em Andradas, que possuem uma identidade baseada na tradição do vinho, marcada pela descendência italiana (KALIL, 2016, p.64)
} 
Para Amaral e Barth (2013), devemos aprofundar o conceito de patrimônio, relacionando-o não apenas com o conjunto arquitetônico, mas com o patrimônio cultural da comunidade, gerando assim novos potenciais de utilização desses espaços para o lazer, à cultura e ao turismo na região.

A cultura da uva e do vinho construiu uma marca nos sujeitos e na sociedade das regiões onde centenas de milhares de pessoas construíram e constroem suas vidas. Nesse contexto, os elementos materiais e imateriais da vitivinicultura são expressão cultural, cuja paisagem vitícola distingue e identifica os territórios (FALCADE, 2017).

Mediante o exposto, acreditamos na existência de um Patrimônio Territorial da uva e do vinho no sul de Minas Gerais. Sendo o patrimônio territorial como aquelas territorialidades contidas na ruralidade, e que expressam identidades cristalizadas historicamente no território.

\begin{abstract}
As identidades são produtos dos processos históricos e relacionais, ou seja, da formação de cada território num contexto de relações sociais com o ambiente externo à vida em sociedade. A identidade, desta maneira, configura-se num patrimônio territorial a ser preservado e valorizado pelos atores envolvidos diretamente na sua constituição histórica e por outras pessoas que podem 'viver' esse patrimônio. O território, então, envolve esse patrimônio identitário: o saber-fazer, as edificações, os monumentos, os museus, os dialetos, as crenças, os arquivos históricos, as relações sociais das famílias, as empresas, as organizações políticas... que pode ser potencializado em projetos e programas desenvolvimento que visem sua preservação e valorização. (SAQUET; BRISKIEVICZ, 2009, p.9) (Grifo nosso).
\end{abstract}

Ao resgatar a memória e as práticas associadas a vitivinicultura no sul de Minas Gerais/Brasil, trazemos à tona a potencialidade da temática que muitas vezes é associada apenas ao sul do país negligenciando outros territórios da uva e do vinho existentes no território brasileiro. Reconhecer o estado de Minas Gerais enquanto produtor de vinhos, é antes de mais nada reconhecer a existência secular de um certo modo de saber/fazer associada a uma ruralidade que se expressa na produção artesanal e no seu caráter familiar.

O patrimônio cultural da vitivinicultura no sul mineiro se expressa de maneira plural e difusa. As marcas desse patrimônio são visíveis na paisagem, embora boa parte dos antigos parreirais estejam em declínio. O patrimônio material em forma de antigas adegas é o registro histórico do tempo áureo dessa atividade no município de Andradas. O patrimônio imaterial está nas memórias dos descendentes de imigrantes italianos que por décadas produziram o vinho colonial, e que apesar dos novos conceitos da vitivinicultura a tradição se mantém.

\title{
3. As paisagens residuais e as taperas do vinho
}

Os vinhedos como elementos que caracterizaram a ruralidade nos municípios de Caldas e Andradas já foram mais representativos. Essas marcas na paisagem tiveram seu auge até final da década de 1960 quando a

Para0nde!?, Porto Alegre, v.13, n.1, p.01-20, 2020. http://seer.ufrgs.br/paraonde 
vitivinicultura se configurava enquanto uma das principais atividades econômica. No entanto, hoje (2018) é notória sua decadência, principalmente o cultivo de uvas americanas para o fabrico de vinhos de mesa.

Todas as paisagens possuem significados simbólicos porque são 0 produto da apropriação e da transformação do meio ambiente pelo homem. O simbolismo é mais facilmente apreendido nas paisagens mais elaboradas - a cidade, o parque e o jardim - e por meio da representação da paisagem na pintura, na poesia, e em outras artes. Mas, pode ser lido nas paisagens rurais e até nas mais aparentemente não humanizadas paisagens do meio ambiente natural. Estas últimas são, frequentemente, símbolos poderosos em si mesmas (COSGROVE, 2012, p. 228)

Esse tempo áureo da vitivinicultura fica explícito em Bellini (1954): realiza-se anualmente nesta cidade, a já tradicional Festa e Exposição de Uvas, Vinhos e Derivados [...] $\mathrm{Na}$ época deste magno certame, Caldas vive dias alegres e festivos de sua história vinícola. Suas praças se abarrotam de carros dos mais variados tipos e o povo se acotovela nas praças durante toda semana, afim de ter o prazer de apreciar a exposição de mais de 400 qualidades variadas de uvas como também para saboreá-las.

Portanto estamos diante de um processo que podemos denominar de paisagens residuais da vitivinicultura nos municípios pesquisados. Foi muito notório durante a pesquisa de campo a presença de vinhedos e adegas abandonados. Em Caldas nos distritos rurais da Bocaina e Bom Retiro esse processo ficou muito explícito. Ainda são verificados pequenos vinhedos presentes na paisagem, como se observa nas figuras 1 e 2 .

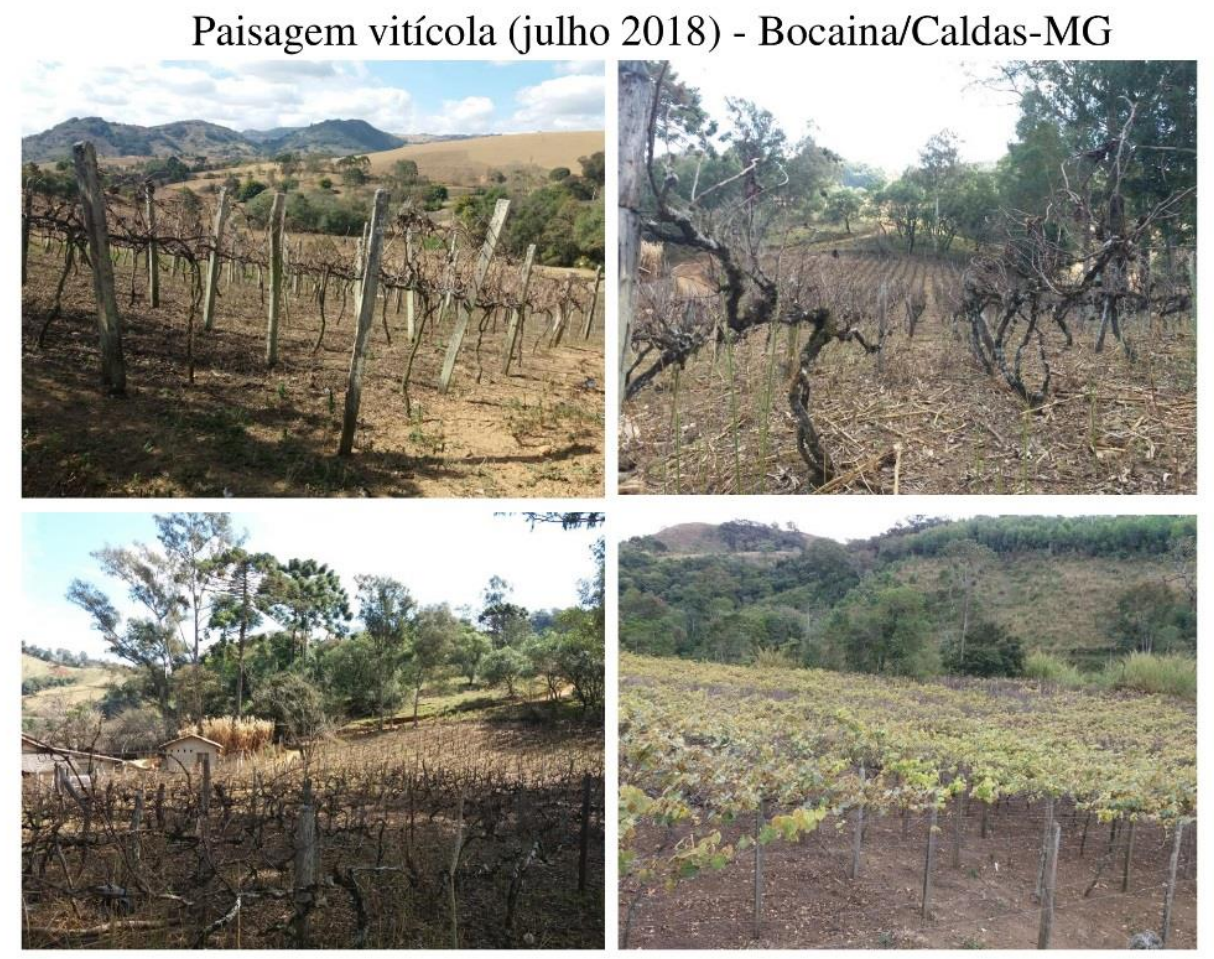

Fonte: Pesquisa de campo (2018) 


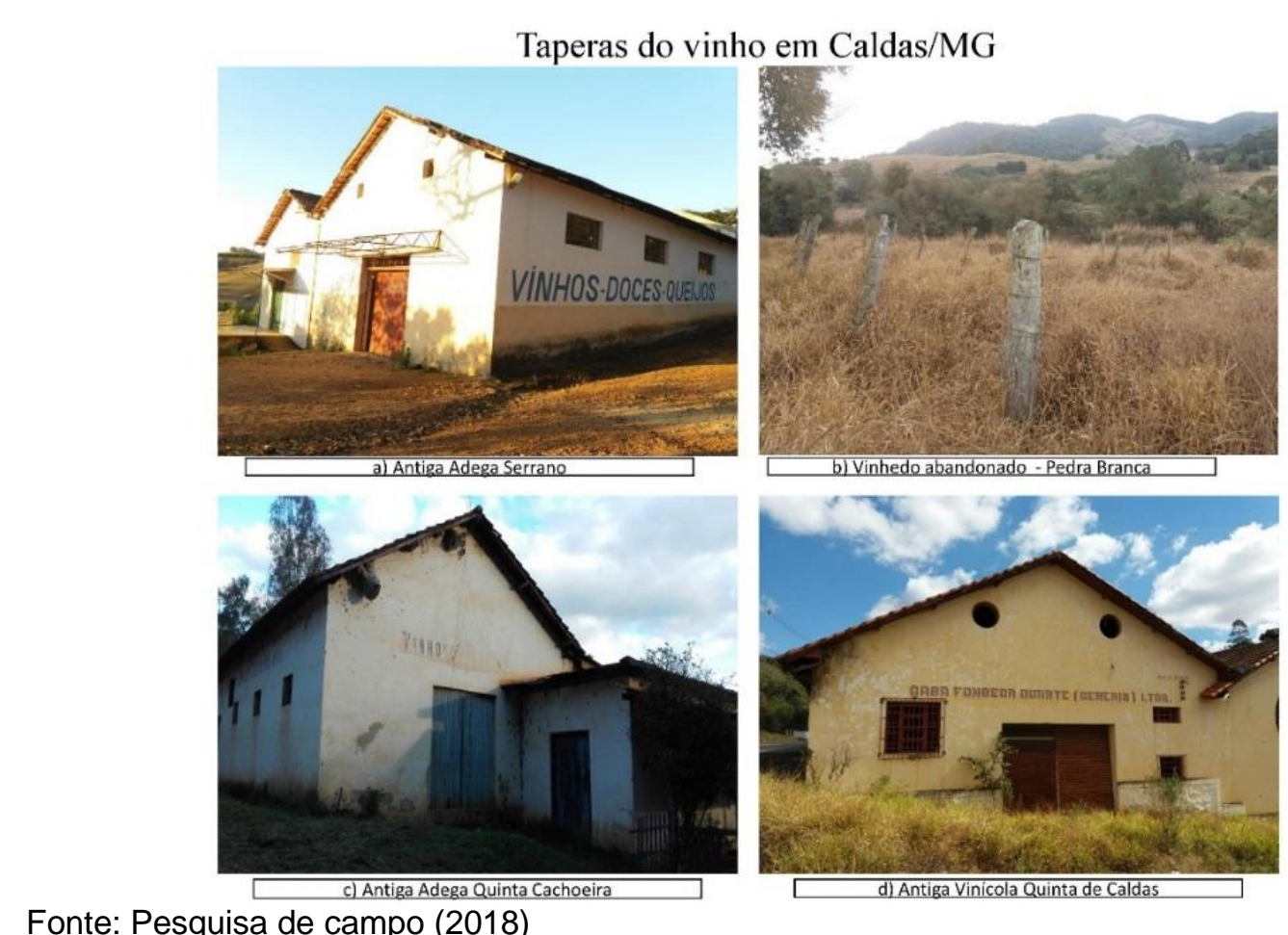

Fonte: Pesquisa de campo (2018)

Paisagem vitícola (julho 2018) - Bom Retiro/Caldas-MG
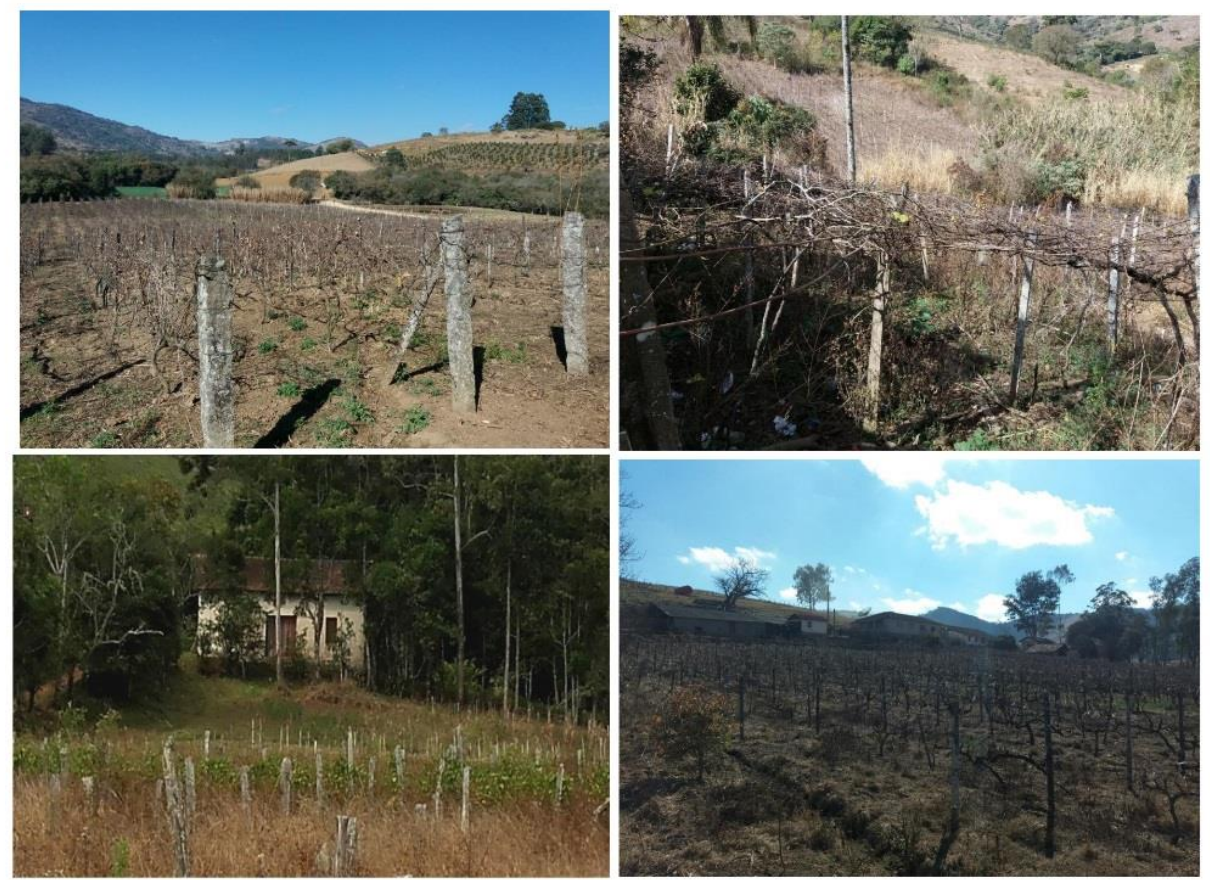

Fonte: Pesquisa de campo (2018)

O elemento residual mais presente na paisagem de Caldas são vinhedos e vinícolas abandonados, ou seja, taperas do vinho. Para Cosgrove (2012) há muito trabalho interessante a ser realizado sobre paisagens do passado e seus significados contemporâneos.

Taperas são lugares abandonados que povoam o imaginário da população do campo e testemunham um tempo que as relações com a terra estavam impregnadas de afetividade. Rompido os vínculos entre pessoas e lugares, 
resta a migração para a cidade ou a extinção da família redesenhando as paisagens desoladas das ruínas (DE DAVID, 2014).

Como exemplo podemos citar a antiga vinícola Caruso Mac Donald, sendo a primeira fábrica de vinhos em padrões industriais de Urussanga/SC, que se encontra em estado crítico de conservação. No centro histórico da cidade os imigrantes italianos fundaram outra duas vinícolas: uma já demolida e a Vinícola Irmãos Cadorin foi tombada. No entanto, a vinícola Caruso Mac Donald não foi tombada e não possui tipo algum de salvaguarda. Esse patrimônio encontra-se em situação emergencial em função da degradação decorrente do seu abandono. (AMARAL; BARTH, 2013).

As taperas do vinho são marcas concretas na paisagem e testemunhas de um tempo em que a vitivinicultura era principal atividade econômica, como fica evidenciado no informativo da prefeitura de Caldas. "Hoje cultiva-se, em Caldas cerca de 200 castas de uvas e, de 49 adegas existentes, o suco generoso dos parrerais, é complemento indispensável à boa mesa" (PREFEITURA DE CALDAS, 1968).

O mesmo se observa em Andradas, onde a presença das taperas do vinho se faz muito presente na paisagem rural. Portanto, são os elementos residuais da vitivinicultura mais presentes na paisagem.

Taperas do vinho em Andradas-MG

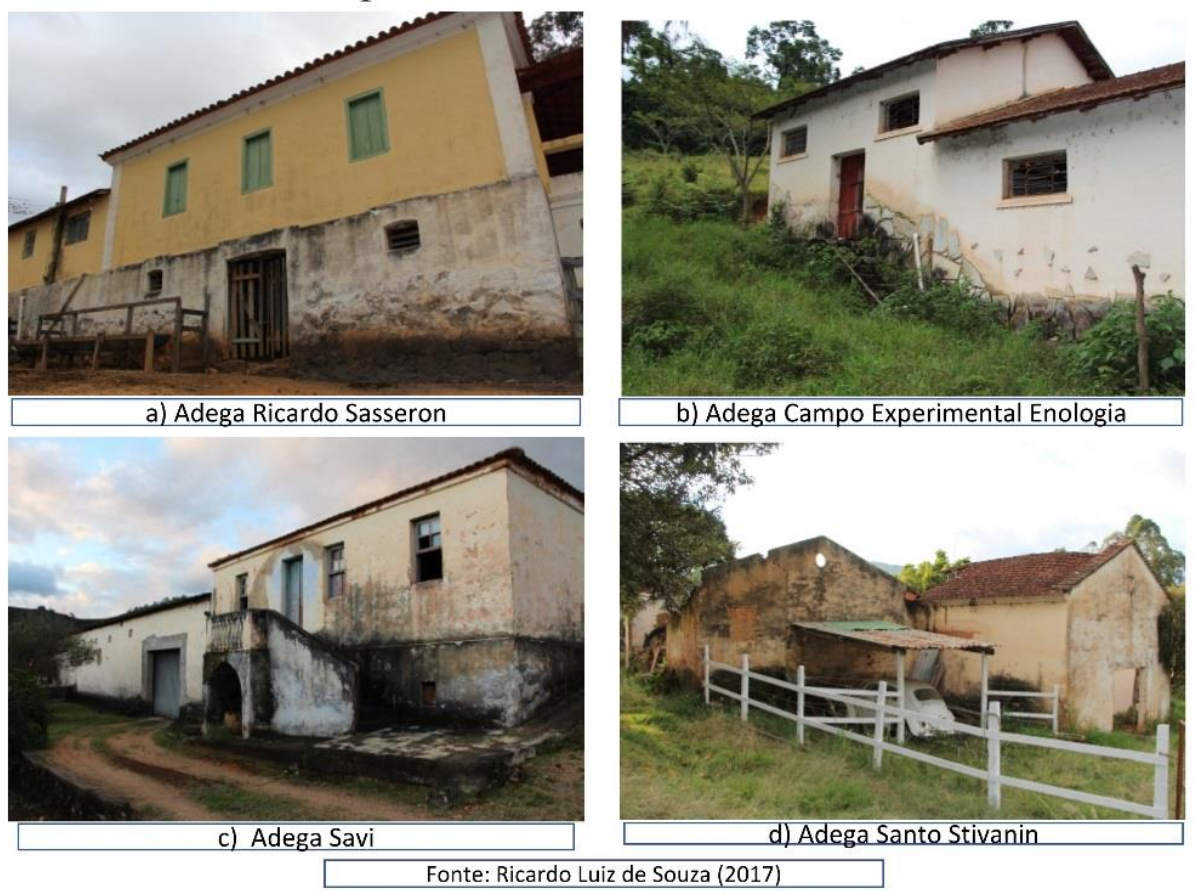

Fonte: Pesquisa de campo (2018)

$\mathrm{Na}$ medida em que o tempo passa, essas taperas como elementos da paisagem vão perdendo seu significado original. Daí reside a importância da pesquisa sobre o patrimônio vitivinícola no sul de Minas Gerais.

Os geógrafos há muito têm interesse por paisagens-relíquias, usando-as geralmente como pistas para a reconstrução de antigas 
geografias. Todavia, como ocorrer com todos os documentos históricos, é difícil recuperar o significado de tais formas para os que as produziram e, na verdade, a interpretação que fazemos deles nos diz tanto sobre nós mesmos e nossas suposições culturais quanto sobre seu significado original (COSGROVE, 2012, p. 233)

A vitivinicultura associada a produção artesanal de vinho de mesa constituise cada vez mais enquanto patrimônio cultural. Daí a importância da salvaguarda de todo essa cultura historicamente associada ao cultivo da uva e do fabrico do vinho.

\section{Os museus do vinho}

O patrimônio histórico pode ser definido como um bem material, natural ou imóvel que possui significado e importância artística, cultural, religiosa, documental ou estética para a sociedade. A Constituição Federal de 1988, constitui e assegura uma proteção específica ao patrimônio cultural, passando a abranger não só os bens de natureza material como também os imateriais; além de conjuntos urbanos e sítios de valor histórico, paisagístico, artístico, arqueológico, paleontológico, ecológico e científico.

De maneira geral existe um deslocamento discursivo e de objeto no campo do patrimônio ${ }^{2}$ nas últimas décadas, passando de uma abordagem relacionada ao patrimônio histórico e artístico para o patrimônio cultural; do patrimônio como expressão artística e histórica de um grupo e manifestação de uma identidade nacional, ao patrimônio como prática da cidadania (RIBEIRO, 2017).

É nesse contexto que outras perspectivas de patrimônio vão sendo valorizadas, principalmente aquelas ligadas a determinadas comunidades, muitas vezes marginalizadas pela cultura dominante, mas que possuem especificidades em sua forma de saber e de fazer. Mediante esse quadro estamos vivenciando um momento muito profícuo de revitalização e reinterpretação da especificidade cultural.

Se outrora a patrimonialização tinha relação direta com a dimensão material, nas últimas décadas a perspectiva imaterial tem avançado significativamente. Um exemplo dessa questão é o reconhecimento da paisagem enquanto patrimônio cultural. Mais especificamente, podemos citar a paisagem vitivinícola na Europa, como é o caso da região do Douro em Portugal.

Nesse contexto, tanto a Espanha como Portugal pela larga tradição vitivinícola, existem muitos museus temáticos enquanto patrimônio cultural, contribuindo como elementos importantes para o desenvolvimento econômico e social onde estão inseridos. Para Cavicchioli (2013) um importante meio capaz de conferir maior visibilidade ao patrimônio cultural do vinho, ao mesmo tempo em que o preserva, são as rotas turísticas e os museus.

Dentre as várias contribuições desses museus para o patrimônio cultural

${ }^{2}$ A discussão sobre a moderna política de patrimônio cultural nasce no século XIX na Europa. Para maiores detalhes consultar CHOAY, F. (2001) A alegoria do patrimônio. São Paulo: Estação liberdade, Unesp.

Para0nde!?, Porto Alegre, v.13, n.1, p.01-20, 2020. http://seer.ufrgs.br/paraonde 
vitivinícola, podemos destacar: (a) os museus enquanto espaços de divulgação do património cultural (material e imaterial); (b) promovem a valorização e a divulgação da cultura do vinho; (c) promovem o enoturismo, pois oferecem mais recursos culturais e turísticos. A seguir são listadas algumas experiências de museus na escala internacional (Quadro 1).

Quadro 1 - Museus do Vinho na escala internacional

\begin{tabular}{|c|c|c|}
\hline Nome & Localização & Caracterização \\
\hline $\begin{array}{l}\text { Museu do Vinho e } \\
\text { do Comércio de } \\
\text { Bordeaux }\end{array}$ & Bordeaux, França & $\begin{array}{l}\text { Construído em } 1720 \text { pelo irlandês Francis Burke, } \\
\text { inicialmente para ser uma loja de vinhos, está aberto } \\
\text { ao público desde junho de } 2008 \text {. Contém uma vasta } \\
\text { coleção de objetos históricos e documentos } \\
\text { retratando o comércio dos vinhos Bordeaux desde a } \\
\text { ldade Média }\end{array}$ \\
\hline $\begin{array}{l}\text { Museu do vinho de } \\
\text { Koutsoyannopoulos }\end{array}$ & Vothonas, Grécia & $\begin{array}{l}\text { Localizado dentro de uma cavidade de } 8 \text { metros de } \\
\text { profundidade, é o único museu de vinhos do país. Os } \\
\text { visitantes são levados para um tour sobre a história } \\
\text { do vinho e seus produtores desde } 1600 \text {, enquanto } \\
\text { apreciam a coleção de artefatos históricos } \\
\text { relacionados à bebida. }\end{array}$ \\
\hline $\begin{array}{l}\text { Museu do vinho da } \\
\text { Califórnia }\end{array}$ & Santa Rosa, EUA & $\begin{array}{l}\text { O museu que abrirá em } 2016 \text {, o Wineseum terá nove } \\
\text { galerias com exibições interativas relacionadas à } \\
\text { história da indústria do vinho dos EUA. A coleção do } \\
\text { Wineseum, que possui mais de } 1000 \text { artefatos } \\
\text { históricos. }\end{array}$ \\
\hline $\begin{array}{l}\text { Museu } \\
\text { Internacional do } \\
\text { Vinho }\end{array}$ & Cork, Irlanda & $\begin{array}{l}\text { O pequeno museu situado dentro do Castelo de } \\
\text { Desmond contém uma exibição de artigos históricos } \\
\text { detalhando toda a trajetória da bebida na Irlanda. }\end{array}$ \\
\hline $\begin{array}{c}\text { Museu do Vinho de } \\
\text { Macau }\end{array}$ & Macau, China & $\begin{array}{l}\text { Abriga } 1.143 \text { vinhos diferentes, sendo } 1.115 \\
\text { portugueses e } 28 \text { chineses, com um vinho do Porto } \\
\text { de } 1815, \text { o mais antigo em exposição. O museu } \\
\text { apresenta exemplos de produção de vinho em } \\
\text { Portugal e na China. }\end{array}$ \\
\hline $\begin{array}{l}\text { Museu do vinho } \\
\text { Lugarotti }\end{array}$ & Torgiano, Itália & $\begin{array}{l}\text { Aberto ao público em 1974. Contém arte, cultura e } \\
\text { história dos vinhos da região italiana de Umbria } \\
\text { (região da Itália central, que faz fronteira com } \\
\text { Toscana, Lácio e Marca). O museu possui todos os } \\
\text { artefatos que retratam a rica história da vitivinicultura } \\
\text { na região. }\end{array}$ \\
\hline $\begin{array}{c}\text { Museu do vinho de } \\
\text { Barolo }\end{array}$ & Barolo, Itália & $\begin{array}{l}\text { Aberto ao público em setembro de } 2010 \text {, e criado por } \\
\text { François Confino, o museu mostra como o vinho tem } \\
\text { influenciado a civilização. }\end{array}$ \\
\hline $\begin{array}{c}\text { Museu do Vinho do } \\
\text { Porto }\end{array}$ & Porto, Portugal & $\begin{array}{l}\text { Museu é dedicado a detalhar a história da indústria do } \\
\text { vinho do Porto, e o impacto que teve no } \\
\text { desenvolvimento econômico da cidade. Localizado no } \\
\text { armazém Cais Novo, em um edifício que remonta ao } \\
\text { século } 17 \text {, e que antigamente estocava os vinhos da } \\
\text { Companhia Geral da Agricultura e das Vinhas do Alto } \\
\text { Douro. }\end{array}$ \\
\hline $\begin{array}{c}\text { Museu de Vinho da } \\
\text { Bulgária }\end{array}$ & Pleven, Bulgária & $\begin{array}{l}\text { O único museu de vinhos da Península do Balcãs foi } \\
\text { fundado em 2008, no parque Kalayka. Pleven é } \\
\text { considerado um dos principais centros de conexões } \\
\text { em vinho na Bulgária. }\end{array}$ \\
\hline Museu da Cidade & & Museu em construção, com previsão de inauguração \\
\hline
\end{tabular}

Para0nde!?, Porto Alegre, v.13, n.1, p.01-20, 2020. http://seer.ufrgs.br/paraonde 


\begin{tabular}{|c|c|c|}
\hline $\begin{array}{c}\text { de Civilização dos } \\
\text { vinhos }\end{array}$ & Bordeaux, França & $\begin{array}{c}\text { para o fim de 2016. O complexo vai abrigar, além do } \\
\text { museu, uma galeria e um espaço cultural, todos } \\
\text { abrangendo assuntos sobre vinhos. }\end{array}$ \\
\hline Museu Vivanco & Rioja, Espanha & $\begin{array}{c}\text { Inaugurado em 2004, com coleções de artigos } \\
\text { relacionados a vinhos adquiridas ao longo dos anos } \\
\text { pela família Vivanco, incluindo vasos e ferramentas } \\
\text { agrícolas, e grandes obras de arte ao lado de meios } \\
\text { audiovisuais, para os visitantes aprenderem sobre a } \\
\text { história e o futuro do vinho. }\end{array}$ \\
\hline
\end{tabular}

Fonte: http://revistaadega.uol.com.br/artigo/dicas-de-12-museus-de-vinhos-paraconhecer 10334.html 2015 acesso em abril 2018

Os elementos e os complexos culturais das regiões vitícolas são uma herança diversificada e dinâmica. Nota-se que, nos últimos anos, houve uma evolução na percepção da importância desse patrimônio cultural brasileiro, como por exemplo, nas vinícolas que criaram pequenos museus para a preservação e a valorização de videiras e vinhos, ferramentas e máquinas, construç.es, fotografias, etc (FALCADE, 2017).

No Brasil as experiências em relação a preservação do patrimônio cultural vitivinícola concentram-se no Rio Grande do Sul, devido a tradição na produção de vinhos como anteriormente já destacamos. No quadro 2, listamos os principais museus do vinho.

Quadro 2 - Experiências de Museus sobre o Vinho no Brasil

\begin{tabular}{|c|c|c|}
\hline Nome & Localização & Caracterização \\
\hline $\begin{array}{l}\text { Museu Padre Alberto } \\
\text { Lamonatto }\end{array}$ & $\begin{array}{l}\text { Flores da Cunha } \\
\text { (RS) }\end{array}$ & $\begin{array}{l}\text { Localizado no distrito de Otávio Rocha, abriga uma } \\
\text { grande coleção de licores e vinhos. O acervo tem } \\
\text { ainda objetos históricos da imigração italiana. } \\
\text { Instalado dentro de um prédio datado de 1935, } \\
\text { todo o acervo do museu foi doado pelo padre } \\
\text { Alberto Lamonatto. }\end{array}$ \\
\hline $\begin{array}{l}\text { Memorial do Vinho } \\
\text { Villa Michelon }\end{array}$ & $\begin{array}{l}\text { Bento Gonçalves } \\
\text { (RS) }\end{array}$ & $\begin{array}{l}\text { Com um acervo de peças utilizadas na colheita da } \\
\text { uva e no processo de elaboração do vinho } \\
\text { pertencentes ao período da colonização que iniciou } \\
\text { por volta de } 1875 \text {. Além de fotos e mapas sobre a } \\
\text { história do vinho no Vale dos Vinhedos, } \\
\text { contemplando registros, imagens e depoimentos de } \\
\text { descendentes diretos dos precursores da } \\
\text { vitivinicultura na região. }\end{array}$ \\
\hline $\begin{array}{l}\text { Museu Municipal da } \\
\text { Uva e do Vinho } \\
\text { Primo Slomp }\end{array}$ & Caxias do Sul (RS) & $\begin{array}{l}\text { No Museu pode-se viajar no tempo e conhecer o } \\
\text { processo pelo qual a uva passava até se } \\
\text { transformar em vinho através de registros } \\
\text { fotográficos, equipamentos de trabalho, processos } \\
\text { de cultivo e utensílios da vinha.O local funciona } \\
\text { junto a Cooperativa Forqueta - a } 1^{\text {a }} \text { da América } \\
\text { Latina - e conta com } 156 \text { peças, provenientes de } \\
\text { várias e extintas vinícolas de Caxias do Sul. }\end{array}$ \\
\hline $\begin{array}{l}\text { Ecomuseu da cultura } \\
\text { do vinho Dal Pizzol }\end{array}$ & $\begin{array}{l}\text { Bento Gonçalves } \\
\text { (RS) }\end{array}$ & $\begin{array}{l}\text { O Ecomuseu disposto em uma área de } 80 \text { mil } \\
\text { metros quadrados compreende lagos e áreas } \\
\text { verdes e visa consolidar a tradição secular e } \\
\text { milenar da civilização do vinho na região da Serra } \\
\text { Gaúcha, principalmente como um atrativo para o } \\
\text { enoturismo. Abriga também uma coleção } \\
\text { ampelográfica privada, em campo, com cerca de }\end{array}$ \\
\hline
\end{tabular}

Para0nde!?, Porto Alegre, v.13, n.1, p.01-20, 2020. http://seer.ufrgs.br/paraonde 


\begin{tabular}{|l|l|l|}
\hline & & 400 variedades de uvas, de 30 países. \\
\hline $\begin{array}{l}\text { Espaço Cultural } \\
\text { Museu do Vinho }\end{array}$ & $\begin{array}{l}\text { Conta a história da vitivinicultura e a chegada dos } \\
\text { italianos na região, foi montado em 2002 por } \\
\text { iniciativa da família Brunholi. No local é possível } \\
\text { encontrar painéis contando a história dividida em } \\
\text { famílias, imigração e uva e vinho, além de } \\
\text { utensílios de uso doméstico e produção de vinho. }\end{array}$ \\
\hline
\end{tabular}

Dos 5 museus listados no Brasil, apenas um está localizado fora do Rio Grande do Sul. O espaço Cultural Museu do Vinho de Jundiaí localizado no interior paulista registra a relação entre a vitivinicultura e a imigração italiana nessa região. Portanto, o Museu do Vinho de Andradas preencherá essa lacuna, ao registrar as expressões e o patrimônio cultural da vitivinicultura no sul de Minas Gerais.

\subsection{O museu do vinho de andradas}

O sudeste brasileiro se comparado ao sul do Brasil, em especial o estado do Rio Grande do Sul, não tem a mesma importância econômica e histórica em relação a vitivinicultura. No entanto, podemos destacar duas regiões com tradição no cultivo de uvas para a fabricação de vinhos, sendo uma em São Roque no interior de São Paulo, e outra no sul de Minas Gerais, em especial no município de Andradas.

É nesse contexto que se localiza a Adega Izidro (Foto 1) representa o auge da produção de vinhos em Andradas, que foi entre as décadas de 60 e 80 . A vinícola foi inaugurada em 1959, seguindo os padrões e técnicas de produção do Vinho tipo Madeira, empresa proveniente da llha da Madeira. Andradas foi - local no Brasil escolhido pela empresa portuguesa por reunir todas as características que possibilitariam um vinho com a qualidade do produzido na Ilha da Madeira (PREFEITURA MUNICIPAL, 2018).

Foto 1: Andradas/MG - Antiga Adega Izidro Gonsalves

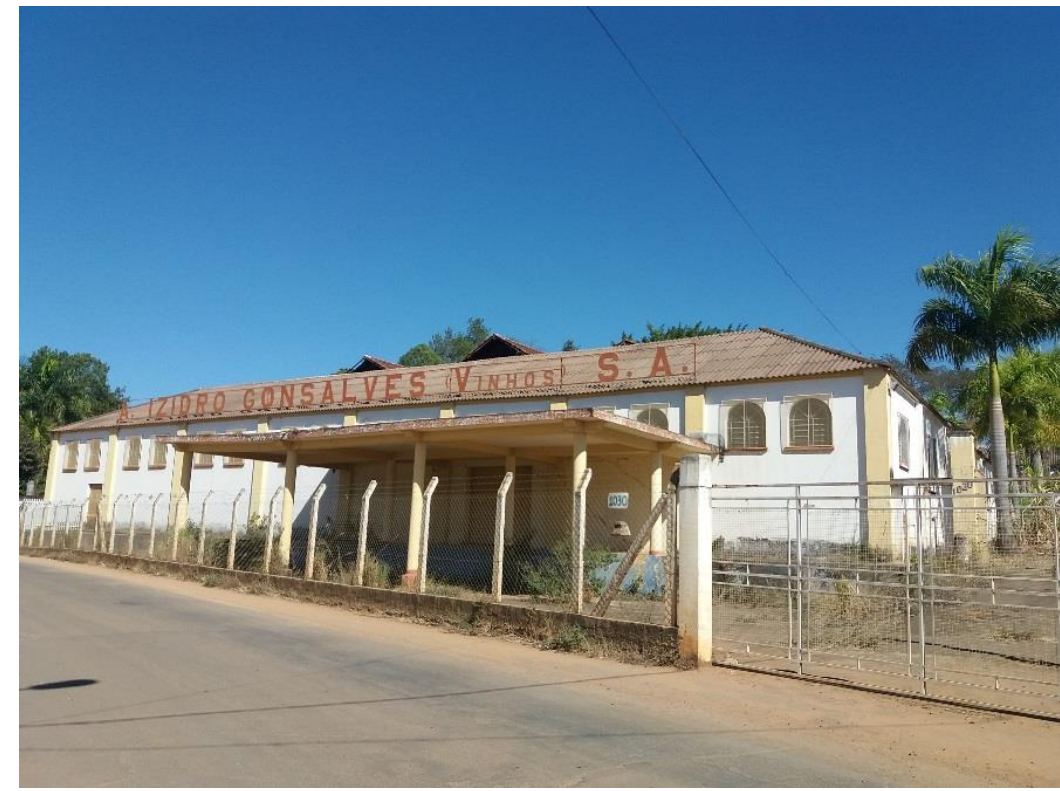

Fonte: Pesquisa de Campo em Andradas (Julho, 2018)

Para0nde!?, Porto Alegre, v.13, n.1, p.01-20, 2020. http://seer.ufrgs.br/paraonde 
Nesse contexto, ao reconhecer a antiga adega enquanto patrimônio cultural, as futuras gerações poderão ter acesso aos aspectos do passado que foram e são muito importantes para o município. Embora esteja em processo de reestruturação, a vitivinicultura em Andradas não pode ser negligenciada em seus aspectos históricos, pois imprimiu no território e na paisagem suas expressões, sejam por meio de parreirais, das adegas, e um modo de fazer vinho.

Considera-se como uma ameaça à preservação das antigas vinícolas o abandono das atividades tradicionais relativas à produção de vinho. A desativação da produção vinícola implicou o abandono dos edifícios. Levando em conta que o resgate dessa atividade pode se tornar inviável, julga-se relevante a utilização dessas construções para outros usos adequados, garantindo ao menos a conservação e a salvaguarda dessas edificações industriais. Acredita-se que as potencialidades enoturísticas estão ligadas ao seu patrimônio material e também imaterial, devendo-se levar em consideração o potencial de novos usos dessas edificações e os vínculos com a paisagem e a história da região (BARTH; AMARAL, 2015).

Para Tedesco (2013) dar visibilidade aos vestígios, às memórias de lugares e aos lugares de memória, é quase que um imperativo na sociedade atual, pois vivemos num período de ameaça das identidades, de substituições de tempos e lugares, de encurtamento de distância, de massificação de registros, de tempos com dimensões lineares.

Portanto, é nesse contexto que está em curso o projeto do museu do vinho de Andradas, visando valorizar e preservar a história das vinícolas é de suma importância para a cidade, pois a sua conservação e valorização é a força motriz para a conservação da memória coletiva da cidade e de seus cidadãos. Valorizar as raízes é criar identidade e pertencimento de todas as pessoas envolvidas, aguçando o senso crítico e o exercício da cidadania (PREFEITURA MUNICIPAL, 2018).

As instituições museais passam a existir nas relações com a sociedade, nas suas mais diversas fragmentações e segmentações, a responder a reivindicações sociais crescentes para participação nos processos de musealização e a aprender a lidar com o direito de grupos a tecer suas microhistórias, construir suas memorias, eleger e preservar seus patrimônios (CURY, 2013).

A proposta do Museu do Vinho de Andradas levará em consideração o processo histórico da instalação e desenvolvimento da vitivinicultura no munícipio de Andradas, entre o final do século XIX e ao decorrer do século XX, destacando a relação econômica entre a imigração italiana e 0 desenvolvimento vinícola. Outro marco foi a construção e operação da Subestação de Enologia pelo Estado Novo Varguista, além da primeira Festa do Vinho de 1954. O plano museológico resgatará a importância histórica da vitivinicultora para o município, reforçando assim um sentimento de pertencimento e de valorização dos patrimônios históricos (PLANO MUSEOLÓGICO, 2018).

O tombamento das instalações da antiga adega Izidro Gonsalves pelo poder

Para0nde!?, Porto Alegre, v.13, n.1, p.01-20, 2020. http://seer.ufrgs.br/paraonde 
público municipal insere Andradas no circuito nacional e internacional do patrimônio industrial, principalmente aquele associado a produção do vinho.

Pensar os museus, como os de temática industrial, em toda a sua abrangência no que toca às suas potencialidades de motor de desenvolvimento. Não somente como um instrumento de activação social, cultural, educativa, lúdica, mas igualmente como um elemento de intervenção política e económica, com plenos poderes de, directa ou indirectamente, servir e influenciar o devir dos diversos sectores da sociedade. A primeira assunção advém do entendimento da própria cultura material que os sustenta como uma dimensão intimamente associada ao futuro dos indivíduos e da comunidade. Desta forma, o património cultural passa a ocupar um papel central nas políticas de desenvolvimento das zonas "deprimidas" e nos programas de revitalização territorial (MADURO; GUERREIRO; OLIVEIRA, 2015, p. 1138)

Portanto, o património industrial sofre um processo de reapropriação ajudando a reconstruir a memória e a consciência coletiva fortalecendo, assim, as amarras identitárias ente a população e o espaço social de produção (MADURO; GUERREIRO; OLIVEIRA, 2015).

A identidade territorial constituída em décadas de cultivo da uva e de fabrico do vinho, denota a particularidade dessa atividade que se desenvolveu distante do tradicional território do vinho no sul do Brasil. O saber fazer vinho no Brasil tropical deve ser registrado e salvaguardado, pois a uva e o vinho forjaram no sul de Minas Gerais um patrimônio vitivinícola, e aí reside uma das importâncias do futuro museu.

\begin{abstract}
As instituições museais passam a existir nas relações com a sociedade, nas suas mais diversas fragmentações e segmentações, a responder a reivindicações sociais crescentes para participação nos processos de musealização e a aprender a lidar com o direito de grupos a tecer suas micro- histórias, construir suas memorias, eleger e preservar seus patrimônios. Também os museus vislumbram que o patrimônio está no território e, além disso, e um conjunto de elementos materiais e imateriais que dialogam entre si, não isolados, e fazem parte da dinâmica cultural (CURY, 2013, p. 472).
\end{abstract}

Um desafio que está posto refere-se à associação ao cultivo da uva e o fabrico do vinho como elementos do passado. Não podemos nos esquecer que nas últimas décadas a produção de vinho colonial tenha declinado em função da modernização dos sistemas de cultivo, das normas sanitárias e da mudança no padrão de consumo que passou a exigir vinhos de melhor qualidade. $O$ futuro museu terá o desafio de não ser apenas uma arqueologia do vinho, e sim representar uma vitivinicultura viva e em transformação.

Reconhecer e salvaguardar a memória da indústria vitivinicultura andradense é, antes de tudo, preservar viva todo o contexto histórico de milhares de pessoas que fizeram suas vidas nos parreirais e nas adegas. Além de tudo, valorizar e preservar a história das vinícolas é de suma importância, pois a sua conservação e valorização é a força motriz para a conservação da memória coletiva da cidade e de seus cidadãos. Valorizar as raízes é criar 
identidade e pertencimento de todas as pessoas envolvidas, aguçando o senso crítico e o exercício da cidadania (PLANO MUSEOLÓGICO, 2018).

A identidade territorial forjada a partir da produção vitivinícola constituiu um rico patrimônio cultural (material e imaterial) em Andradas. Aspectos históricos associados ao modo de fazer o vinho colonial, convivem com os mais modernos métodos de produção de vinhos finos. A paisagem vitivinícola também é um patrimônio, pois os parreirais são a expressão de um modo de cultivar a uva. Portanto, a maior riqueza da vitivinicultura no município é a sua diversidade.

Entre as regiões tradicionais e as novas há trocas. Por exemplo, vitivinicultores das regiões tradicionais cultivam nas regiões novas e empresários das regiões novas buscam a experiência das regiões tradicionais. Nos dois casos, a vitivinicultura é expressão da identidade da sociedade que a produz: a tradicional, ligada aos valores culturais da imigração italiana, enquanto a viticultura nova é bem expressão da sociedade técnico-científicainformacional dos dias atuais (FALCADE, 2005).

O museu do vinho poderá ser uma ponte entre a velha forma de produzir vinho herdados dos descendentes dos italianos, com a nova forma associada à produção de vinhos finos de inverno. Dessa maneira a importância do museu do vinho de Andradas ultrapassa as barreiras municipais, configurando-se enquanto um patrimônio cultural que fortalecerá a identidade territorial vitivinícola de todo um território, ou seja, o sul mineiro.

O museu do Vinho de Andradas, embora em fase de implantação, já cumpre com seu papel enquanto repositório de um patrimônio material e imaterial associado a vitivinicultura em Minas Gerais. Ao trazer à tona essa tradição associada ao cultivo da uva e do fabrico do vinho, revela as nossas carências em relação a outras historiografias que não foram contadas, registradas e analisadas. Quem ganha com isso é a sociedade brasileira, na medida em que mais uma parte do nosso processo de formação territorial é revelado.

\section{Considerações finais}

A centenária tradição em cultivar a uva, e realizar o processo de fabrico do vinho, produziram inegavelmente fortes traços identitários sobre o território sul mineiro, em especial nos municípios de Caldas e Andradas, constituindo um considerável patrimônio associado as expressões materiais e imateriais da vitivinicultura.

Nas últimas décadas a área vitícola diminuiu consideravelmente. A tradicional vitivinicultura não acompanhou o processo de modernização da atividade. Apresenta-se como uma atividade em franca decadência, formada pelas paisagens residuais da vitivinicultura, mas com considerável patrimônio material e imaterial.

A partir desse rico patrimônio material e imaterial, a prefeitura de Andradas elaborou um plano museológico que efetivará a criação do Museu do

Para0nde!?, Porto Alegre, v.13, n.1, p.01-20, 2020. http://seer.ufrgs.br/paraonde 
Vinho. Com isso, inserindo o sul mineiro dentro dos roteiros do patrimônio vitivinícola como ocorre em outros lugares no Brasil e no exterior. Ação essa, que culmina com o reconhecimento da vitivinicultura para a formação social e econômica do referido município e do seu entorno.

No sul mineiro a formação de uma identidade associada a vitivinicultura gerou um patrimônio material e imaterial. No entanto, o importante para 0 museu do Vinho de Andradas é contribuir para uma vitivinicultura que está viva e que conecte o passado com o futuro, redesenhando a geografia do vinho como aponta a Cátedra da UNESCO.

\section{Referências}

ARAÚJO, Frederico G. B. de; HAESBAERT, Rogério (Orgs.) Identidades e territórios: questões e olhares contemporâneos. Rio de Janeiro: ACESS, 2007

AMARAL, Tatiana; BARTH, Fernando. Vinícola Caruso Macdonald: Estudo para a restauração das antigas edificações industriais em Urussanga - SC. ANAIS... Colóquio internacional "Vinho, Patrimônio, Turismo e Desenvolvimento. Florianópolis/SC, 03 a 05 de dezembro de 2013.

BATISTA, Elias. Vinho e política: momentos saborosos de grandes estadistas em Andradas. São João da Boa Vista/SP: UNIFAE, 2012.

BARTH, Fernando; AMARAL, Tatiana. Preservação do patrimônio histórico das antigas vinícolas da região sul de Santa Catarina. Resgate - Rev. Interdiscip. Cult., Campinas, v.23, n.30, 2015, p. 17-28, jul./dez

BRANDÃO, Carlos Rodrigues. Vinho amargo: resistência, tradição e modernidade entre sitiantes produtores de uva e vinho no sul de Minas Gerais. Relatório projeto HOSANA, UNICAMP, 1995

CAVICCIOLI, Marina Regis. Desafios e perspectivas na preservação do patrimônio cultural do vinho. ANAIS... Colóquio internacional "Vinho, Patrimônio, Turismo e Desenvolvimento. Florianópolis/SC, 03 a 05 de dezembro de 2013. p. 26

COSGROVE, Denis. A geografia está em toda parte: cultura e simbolismo nas paisagens humanas. In: ROSENDAHL, z.; CORRÊA, R. L (Org.) Geografia cultural: uma analogia. Volume I. Rio de Janeiro: EDUERJ, 2012. p. 219-237

CURY, Marília Xavier. Museu em conexões: reflexões sobre uma proposta de exposição. Revista Ci. Inf., Brasilia, DF, v. 42 n. 3, 2013, p.471-484, set./dez.

DE DAVID, Cesar "O campo se fez tapera..." as paisagens do abandono no espaço rural sul-rio-grandense. In: PIMENTA, M.; FIGUEIREDO, L.C. (Org.) Lugares: patrimônio, memória e paisagens. Florianópolis: Editora UFSC, 2014. p. $75-92$

DUARTE, Tiaraju S.; FERNANDES, Sibeli. Identidade territorial e o enoturismo: a imigração e o fabrico do vinho na colônia Maciel, Pelotas (RS)... ANAIS... IX CITURDES, ECA/USP, 2014.

FALCADE, Ivanira. A geografia da uva e do vinho no Brasil: território, cultura e

Para0nde!?, Porto Alegre, v.13, n.1, p.01-20, 2020. http://seer.ufrgs.br/paraonde 
patrimônio. MEDEIROS, Rosa Maria Vieira; LINDNER, Michele. (Orgs.) A uva e o vinho como expressões da cultura, patrimônio e território. Porto Alegre: IGEO - Instituto de Geociências, 2017. p. 103-123

FALCADE, Ivanira. As paisagens vitícolas e a identidade das indicações de procedência Vale dos Vinhedos, Pinto Bandeira e Monte Belo. In: MEDEIROS, Rosa Maria Vieira; FALCADE, Ivanira (Orgs.) Expressões da re-territorialização no campo brasileiro. Porto Alegre: Imprensa Livre, 2013, p. 257-281

FALCADE, Ivanira. Paisagens vitícolas brasileiras. ANAIS X Congresso Brasileiro de Viticultura e Enologia, 2005.

FLORES, Shana Sabbado; MEDEIROS, Rosa Maria Vieira. Ruralidades na compreensão do território do vinho e sua identidade. Campo-Território: revista de geografia agrária. Uberlândia, v. 8, n. 15, p. 1-19, fev., 2013.

IBGE. Enciclopédia dos municípios brasileiros (XXIV volume). Rio de Janeiro, 1958.

LISBÔA, Janine Basso; BRUCH, Kelly Lissandra (Org.) Vinho colonial: um guia para formalização de agricultores familiares no Estado do Rio Grande do Sul. Bento Gonçalves/RS: IBRAVIN: EMBRAPA; Porto Alegre :MAPA: SAPI: SDRPC: EMATER/RS: UFRGS, 2017.

LUCCA FILHO, Vinícius. Apresentação. ANAIS... Colóquio internacional "Vinho, Patrimônio, Turismo e Desenvolvimento. Florianópolis/SC, 03 a 05 de dezembro de 2013.

MADURO, A. V; GUERREIRO, A.; OLIVEIRA, A. O turismo industrial como potenciador do desenvolvimento local-estudo de caso do Museu do Vinho de Alcobaça em Portugal. PASOS. Revista de Turismo y Patrimonio Cultural. Vol. 13 n. 5. 2015, p.1129-1143.

MEDEIROS, Rosa Maria Vieira; LINDNER, Michele (Orgs). A uva e o vinho como expressões da cultura, patrimônio e território. Porto Alegre: IGEO/UFRGS, 2017.

MEDEIROS, Rosa Maria Vieira. Centro do Patrimônio e Cultura do Vinho/CEPAVIN. MEDEIROS, Rosa Maria Vieira; LINDNER, Michele. (Orgs.) A uva e o vinho como expressões da cultura, patrimônio e território. Porto Alegre: IGEO/UFRGS, 2017

MEDEIROS, Rosa Maria Vieira; LINDNER, Michele (Orgs). Expressões da cultura no território. Porto Alegre: Evangraf, 2015.

KALIL, Thalassa. O vinho em Andradas (MG): sabor, paisagem, lugar, memória e perspectivas dos produtores. Geograficidade, v6, n.2. 2016

PEREIRA, José Augusto. Caldas - cidade das uvas. Caldas,1950 (mimeo)

PAES, Maria T. D.; SOTRATTI, Marcelo A. (Orgs) Geografia, turismo e patrimônio cultural: identidades, usos e ideologias. São Paulo: Annablume. 2017

PLANO MUSEOLÓGICO DO MUSEU DO VINHO DE ANDRADAS. http://www.andradas.mg.gov.br/noticia/1589/plano-museologico-museu-do- 


\section{vinho-de-andradas acesso em 12/03/2018}

PREFEITURA DE CALDAS. Roteiro da Uva - Festa da uva. Comissão de propaganda da Festa da Uva: Caldas, 1968

RIBEIRO, Rafael Winter. (2007) Paisagem cultural e patrimônio. Rio de Janeiro: IPHAN/COPEDOC, 2007.

SAQUET, Marcos A.; BRISKIEVICZ, Michele. Territorialidade e identidade: um patrimônio no desenvolvimento territorial. Caderno Prudentino de Geografia, n-31, vol.1, 2009. p.3-16

SOUZA, Ricardo Luiz de. Zappa, lavoro e vinho (enxada, trabalho e vinho). Os imigrantes italianos e sua importância na vitivinicultura de Andradas (18901954). Casa da Andradas/MG: Casa da Memória, 2018 (Mimeo)

SOMMERS, Brian J. Geografia do vinho. (Tradução Pamela Andrade). Osasco/SP: Novo Século Editora, 2010.

SOTRATTI, Marcelo A.; MARAFON, Glaucio J. A pesquisa qualitativa nos estudos do patrimônio cultural em espaços rurais: desafios e possibilidades. In: MARAFON, Glaucio J. et al (Orgs.) Pesquisa qualitativa em Geografia: reflexões teórico- conceituais e aplicações. Rio de Janeiro: EDUERJ, 2013, p. 191-206

TEDESCO, João C. O futuro do passado: etnicidade, comércio e vida rural tradições culturais em rotas turísticas. Porto Alegre: Letra \& Vida, 2013 